\title{
Screening for hypertension in a Primary Care Dental clinic
}

\author{
Javier Fernández-Feijoo ${ }^{1}$, José-Luis Núñez-Orjales ${ }^{2}$, Jacobo Limeres-Posse ${ }^{3}$, Esther Pérez-Serrano ${ }^{4}$, In- \\ maculada Tomás-Carmona ${ }^{5}$
}

${ }^{1}$ Associate Professor. Special Patients Unit. Department of Medicine and Dentistry. University of Santiago

${ }^{2}$ Dentist. Oral Health Unit of the SAP. Casa del Mar (Management of Primary Care in A Coruña, Gallician Health Service)

${ }^{3}$ Assistant Professor. Special Patients Unit. Department of Medicine and Dentistry. University of Santiago

${ }^{4}$ Dental Hygienist. Special Patients Unit. Department of Medicine and Dentistry. University of Santiago

${ }^{5}$ Professor. Special Patients Unit. Department of Medicine and Dentistry. University of Santiago

Correspondence:

Special Patients Unit

Department of Medicine and Dentistry

University of Santiago de Compostela

C/ Entrerrios s/n

15782 Santiago de Compostela. Spain

jffeijoo@yahoo.es

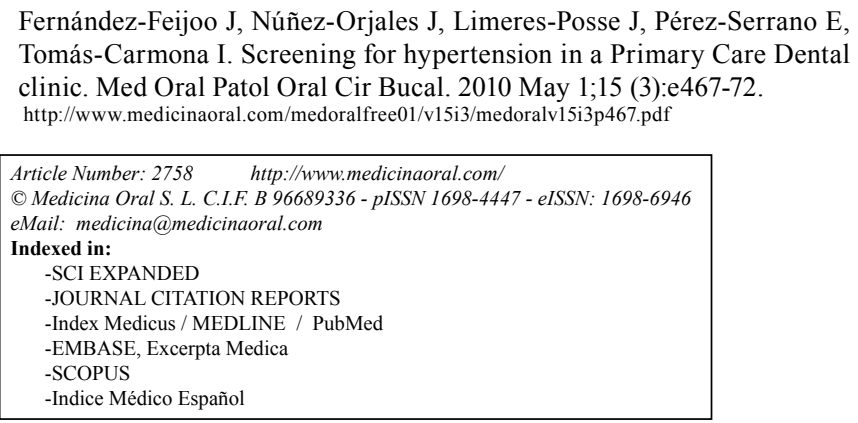

\begin{abstract}
Objective: The aim of this study was to record blood pressure in patients during their visit to a dental clinic, with the aim of identifying those who have high blood pressure and are unaware of it, as well as those who are aware of their condition but do have their blood pressure under adequate control.

Study design: We designed a cross-sectional study which included 154 patients who were seen for a dental checkup at the Primary Dental Care of the Gallician Health Service (SERGAS). All participants completed a standardized medical questionnaire after measuring their systolic blood pressure (SBP) and diastolic blood pressure (DBP), which was conducted using the protocol established by the Spanish Society of Hypertension-Spanish League for the Fight Against Hypertension (HTA).

Results: In 45 patients (29\%), the figures for blood pressure were recorded as SBP $\geq 140 \mathrm{mmHg}$ and/or DBP $\geq 90$ $\mathrm{mmHg}$, indicating that they may have hypertension. Only 12 of them had been previously diagnosed with hypertension, but did not have their blood pressure under adequate control. The remaining 33 had no history of hypertension and were referred to a family physician, but only 19 saw their doctor; 11 of these patients were given non-pharmacological treatment, 6 were prescribed drug treatment and no type of treatment was indicated for the other two patients.

Conclusions: By screening for hypertension, especially among patients who are more than 40 years old, the dentist can play an important role in the early diagnosis.
\end{abstract}

Key words: Hypertension, blood pressure, dentistry, screening. 


\section{Introduction}

High blood pressure (HBP) is one of the major causes of cardiovascular diseases and the leading cause of death in industrialized societies $(1,2)$. As the blood pressure increases, there is a greater possibility of suffering a heart attack, heart failure, stroke and kidney disease. Each increase of 10-20 $\mathrm{mmHg}$ doubles the risk of cardiovascular disease in individuals between the ages of 40 and 70 years old, and whose blood pressure ranges from $115 / 70 \mathrm{mmHg}$ to $185 / 115 \mathrm{mmHg}(3,4)$. The organs most affected by HBP are the vascular system, heart, kidney, brain and eyes (4). Consequently, controlling blood pressure is revealed as the main therapeutic and prophylactic approach for the prevention of these complications.

The prevalence of HBP in Spain is high, estimated at over $30 \%$ of the adult Spanish population, with this percentage increasing significantly for those over the age of 65 years old. It is more common in women. However, not all patients with HBP are recognized as hypertensive (5).

In Spain, the proportion of patients who have their blood pressure under adequate control recording numbers less than or equal to $140 \mathrm{mmHg}$ for systolic blood pressure (SBP) and less than or equal to $90 \mathrm{mmHg}$ for diastolic blood pressure (DBP) while on blood pressure medication, accounts for just under $30 \%$ of the cases. In other countries such as the USA, less than $50 \%$ of patients diagnosed with HBP are being treated medically (6). It has been suggested that taking the blood pressure and reviewing the patient's blood pressure medication should form an integral part of the clinical history at dental clinics $(7,8)$. The cost of the equipment for taking the blood pressure is low (a stethoscope and a mercury sphygmomanometer or aneroid manometer) and, as it is a non-invasive procedure, it can be applied to all population groups (children, adults and seniors).

An ideal program for screening HBP should not only identify cases of undiagnosed hypertension, as well as cases of patients who have been previously diagnosed, but do not have their condition under adequate control. It has been suggested that dentists should collaborate with physicians in this aim, because in most cases, this condition remains asymptomatic for extended periods of time $(4,7,9)$.

The objective of this study was to take the blood pressure of patients during their visit to a dental clinic, with the aim of identifying those who have high blood pressure and are unaware of it, as well as those who are aware of their condition but do not have it under adequate control.

\section{Material and Methods}

The study group consists of 154 patients who came in for a dental checkup at the Primary Dental Care clinic of the Gallician Health Service (SERGAS) during the period ranging from January to June 2008. All participants signed an informed consent for the study and completed a standardized medical questionnaire after taking their blood pressure. The blood pressure was measured in accordance with the protocol established by the working group for the management of hypertension of the European Societies of Hypertension and Cardiology (10), using an aneroid sphygmomanometer (Minimus III Riester 1342) and a stethoscope (Fonendo $\mathrm{T} /$ Littman, Classic $71 \mathrm{~cm}$ Moretti). The blood pressure was measured in a room attached to the dental office, in which the patient remained seated for 5 minutes in a quiet environment, with the arm supported on a table at the height of the middle third of the sternum. We excluded patients who had ingested caffeine within the last hour or who had smoked within 15 minutes prior to taking the blood pressure, or who had a history of consuming exogenous adrenergic stimulants. Each patient received at least 2 readings, within a range of more than 2 minutes. Values of SBP $\geq 140 \mathrm{mmHg}$ and / or DBP $\geq$ $90 \mathrm{mmHg}$ were considered to be suggestive of HBP, according to the classification of blood pressure proposed by the International Committee of Experts, which classifies blood pressure in terms of stages 1 and 2 (4). Those patients who were detected as having high readings each time their blood pressure was measured were referred to their family doctor, whom we later contacted to find out their assessment of the patients referred.

The following variables were analyzed: sex, age, body mass index (BMI: $\mathrm{kg} / \mathrm{m}^{2}$ ), regular medical checks, regular blood pressure checks, family history of hypertension, salt intake, alcohol or tobacco consumption, exercise, general health status, use of blood pressure medication and oral contraceptives.

The results were analyzed with SPSS software version 15.0 for Windows (Inc., Chicago, USA). For the study of qualitative variables, the Fisher's exact test was used. For the study of quantitative variables, the Student $T$ test or the U Mann-Whitney test was used. The choice of a parametric or non-parametric test depended on whether the values of the quantitative variable analyzed showed a normal distribution, which was determined by means of the Kolmogorov-Smirnov test. A multivariate analysis was also conducted using the binary logistic regression method. A p-value $<0.05$ was considered to be statistically significant.

\section{Results}

The 154 patients in the study group ranged in ages between 15 and 84 years old. Among these patients, 91 (59.1\%) were female and $63(40.9 \%)$ were male.

In 45 patients (29.2\%), the figures for blood pressure were recorded as SBP $\geq 140 \mathrm{mmHg}$ and / or DBP $\geq 90$ $\mathrm{mmHg}$, indicating the possibility of hypertension. Only 
12 of them had been previously diagnosed with hypertension, but did not have their blood pressure under adequate control. The remaining 33 did not have a history of HBP. In 33 patients, a definitive diagnosis of stage 1 high blood pressure was made, and 12 were diagnosed with stage 2 (Table 1).

Patients with significantly high blood pressure readings were referred to their family doctor, but only 27 of the 45 were seen by their doctor. Of those who went to their doctor, 12 (44.5\%) were prescribed a non-pharmacological treatment, $6(22.2 \%)$ were prescribed blood pressure medication, and $6(22.2 \%)$ continued with their previous blood pressure treatment, $2(7.4 \%)$ were not prescribed any treatment, and the last patient (3.7\%) was prescribed a medication that was different from the previous treatment.

If we analyze only the 33 patients with pathological blood pressure values that were unaware of their potential high blood pressure condition and were referred to their family doctor, only 19 made the appointment and were seen by their doctor. Of these patients, 11 (58\%) were prescribed non-pharmacological treatment, $6(31.5 \%)$ were prescribed pharmacological treatment, and no type of treatment was prescribed for the other 2 (9.5\%) (Fig. 1).
Ultimately, 3.8\% of the participants (with no prior diagnosis of HBP) were diagnosed as hypertensive and require specific pharmacological treatment.

Of the 12 patients who were known to have hypertension and who were referred to the doctor, 8 made the appointment and were seen by their doctor. Among them, $6(75 \%)$ were told to stay with the same treatment, 1 $(12.5 \%)$ of the patient's non-pharmacological treatment was intensified and the other patient's (12.5\%) pharmalogical treatment was modified (Fig. 1).

In the univariate analysis of potential "risk factors" associated with the presence of HBP among patients with normal blood pressure and patients with HBP, only the following factors were found to be statistically significant:

- Age: patients with normal blood pressure were significantly younger than those with hypertension (43 versus 54 years, $\mathrm{p}=0.001)$. When distributing the patients by decades of age, we see that as of the 40 year mark, the likelihood for hypertension ranges between $32 \%$ and $50 \%$ (Table 2).

- Weight: patients with normal blood pressure weigh significantly less than those with hypertension (68 versus $78 \mathrm{Kg}, \mathrm{p}=0.001)$.

Table 1. Distribution of the study group according to the stage of hypertension ( $\mathrm{n}=154)$.

\begin{tabular}{|l|c|c|c|}
\hline \multicolumn{1}{|c|}{$\begin{array}{c}\text { Classification of the } \\
\text { hypertension }\end{array}$} & SDP mm Hg & DBP mm Hg & Patients (n) \\
\hline Normal & $<120$ & $<80$ & 45 \\
\hline Pre-hypertension & $120-139$ & $80-89$ & 64 \\
\hline Hypertension Stage 1 & $140-159$ & $90-99$ & 33 \\
\hline Hypertension Stage 2 & $>160$ & $>100$ & 12 \\
\hline
\end{tabular}

$\mathrm{SBP}=$ systolic blood pressure DBP $=$ diastolic blood pressure.

Table 2. Distribution of the study group according to age, sex and blood pressure values ( $\mathrm{n}=154)$.

\begin{tabular}{|l|c|c|c|c|c|c|}
\hline $\begin{array}{l}\text { AGE } \\
\text { (years) }\end{array}$ & \multicolumn{3}{|c|}{ HIGH BLOOD PRESSURE } & \multicolumn{3}{c|}{ NORMAL BLOOD PRESSURE } \\
\hline & WOMEN & MEN & TOTAL & WOMEN & MEN & TOTAL \\
\hline $15-24$ & - & - & - & 12 & 5 & $17(100 \%)$ \\
\hline $25-34$ & 2 & 2 & $4(12.5 \%)$ & 19 & 9 & $28(87.5 \%)$ \\
\hline $35-44$ & 4 & 3 & $7(41.1 \%)$ & 5 & 5 & $10(58.9 \%)$ \\
\hline $45-54$ & 7 & 7 & $14(46.7 \%)$ & 13 & 3 & $16(53.3)$ \\
\hline $55-64$ & 5 & 4 & $9(32.1 \%)$ & 8 & 11 & $19(67.9 \%)$ \\
\hline $65-74$ & 7 & 5 & $12(50 \%)$ & 5 & 7 & $12(50 \%)$ \\
\hline$\geq 75^{*}$ & - & - & - & 4 & 2 & $6(100 \%)$ \\
\hline
\end{tabular}

* The 6 patients $\geq 75$ years old had pre-hypertension. 


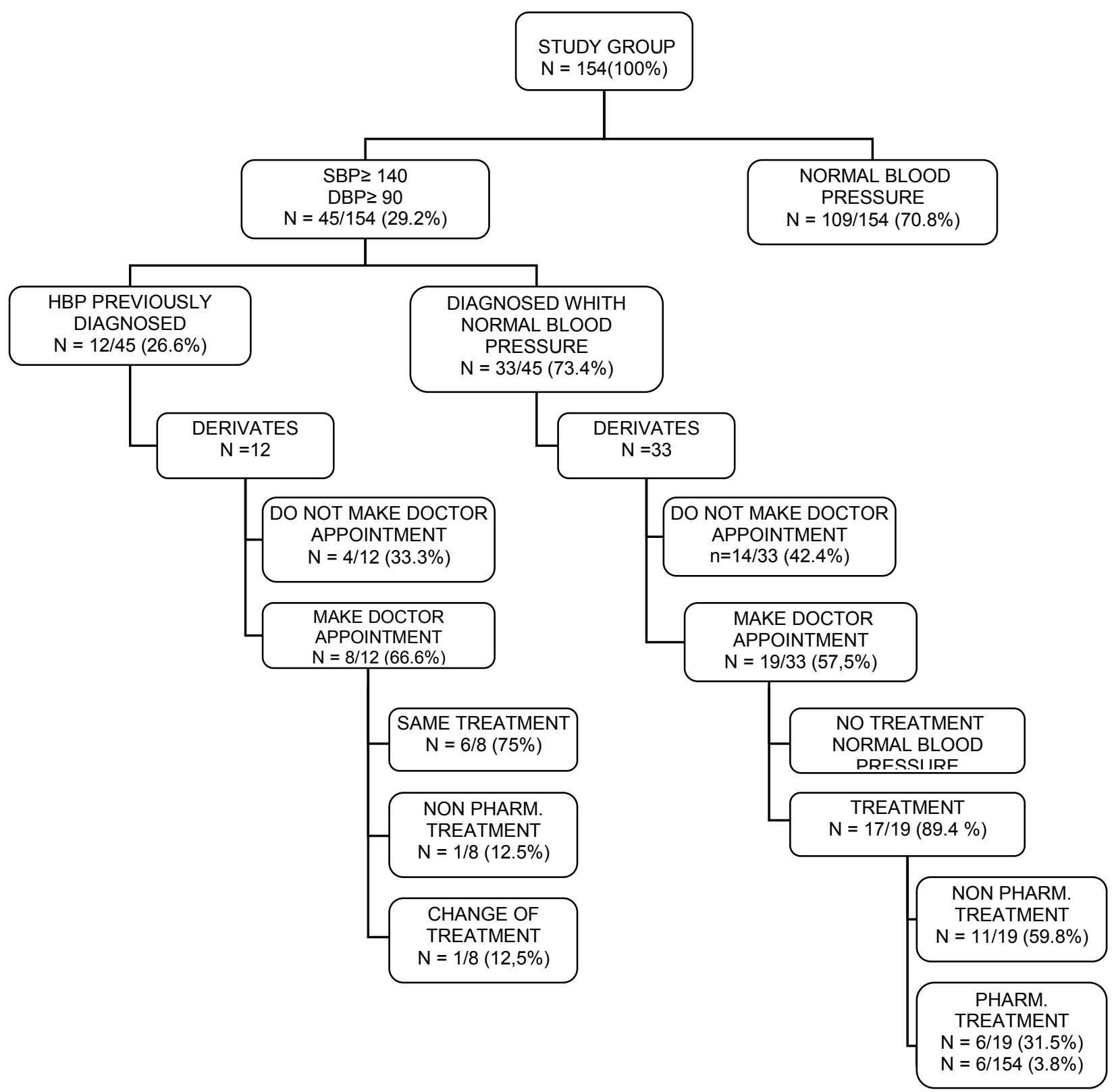

Fig. 1. Distribution of the study group according to the blood pressure values obtained, frequency of reading and pres-cription of blood pressure medication. 
- Heart rate: patients with normal blood pressure have a significantly lower heart rate than those who are hypertensive ( 75 versus 80 beats / $\min , \mathrm{P}=0.02$ ).

- Body mass index: patients with normal blood pressure have a body mass index significantly lower than those with hypertension (26 versus $29, \mathrm{P}<0.001$ ).

- Phsical exercise: the percentage of patients with normal blood pressure who got regular physical exercise was significantly greater than in the case of patients with hypertension ( $41.3 \%$ versus $15.6 \%, \mathrm{p}=0.001$ ).

- Of the variables that were found to be statistically significant in the univariate analysis, and also maintained their significance in the multivariate analysis, were: age ( $p=0.008)$, weight $(p=0.003)$, heart rate $(p=0.005)$ and physical exercise $(p=0.018)$.

\section{Discussion}

The prevalence of hypertension in our study $(29.2 \%)$ was similar to that obtained by Tormo et al. (5) (34.3\%) in a study by the Spanish cohort EPIC (European Prospective Study on Diet, Cancer and Health). The effect of the raising of blood pressure when it is recorded in a medical office (white coat hypertension) seems unlikely in our series because our results are consistent with the prevalence of hypertension in the general Spanish population, as confirmed by other studies (5).

Miyawaki et al. (11), detected a percentage of patients with HBP who were seen at dental clinics as $25.9 \%$, compared to $29.2 \%$ in our study. If we only consider patients whose hypertension was previously unknown, the results obtained by these authors were also very similar to those found in our study $(20.4 \%$ and $21.4 \%$, respectively). Recently, Thompson et al. (12) identified only $14 \%$ of hypertensive patients among those the patients at the Department of Dental Hygiene School in Augusta, Georgia (USA), but the blood pressure readings used by these authors are not comparable to those of this series, as they introduced the concept of pre-hypertension, with a prevalence of $60 \%$ in their study group.

In a paper published by Berman et al. (1), only $13 \%$ of patients had no prior knowledge of HBP, but had readings that were indicative of HBP and were referred for medical evaluation, but found to have blood pressure within the normal range. In the present study, $10.5 \%$ of patients who had blood pressure consistent with that of HBP (and did not know it) and who sought medical treatment, were not prescribed treatment, as they were found to have blood pressure within the normal range. We also agree with Berman et al. (1), in which $34.9 \%$ of patients referred for a medical exam by the doctor due presenting figured indicative of a blood pressure pathology following the reading at the dental clinic, were prescribed blood pressure medication, compared to $31.5 \%$ of the patients in our study.
Among the $77 \%$ of patients known to have HBP, who were referred to their doctor, no changes were made in their treatment. It has been pointed out that a high percentage of those with poorly controlled hypertension do not take any measures to try to bring their blood pressure under control, and the Spanish doctors tend to adopt a conservative attitude without making any changes in therapy (13).

Also, in terms of the percentage of the total number patients who needed medication, our figures were very similar to those found by Abbey (14), who noted that 5\% of the patients in his sample were clinically diagnosed as hypertensive after their appointment with the doctor.

In our study, age appears as one of the factors directly related to increased blood pressure. This, combined with the fact that those who are elderly often present comorbidities, indicates that the sum of two factors such as age and HBP may be the most important medical risk factors in patients undergoing dental treatment (11).

As of 55-60 years of age, an increased prevalence of HBP has been observed, which exceeds $65 \%$ in those older than 60-65 years (15). For individuals between 40 and 70 years of age, each increment of $20 \mathrm{mmHg}$ in SBP or $10 \mathrm{mmHg}$ in DBP, doubles the risk of cardiovascular disease in the entire range from $115 / 75$ to $185 / 115$ $\mathrm{mmHg}(3,4)$. Of the 45 hypertensive patients identified in this study, $28(62.2 \%)$ were over the age of 50 years old, although the prevalence of HBP for those over the age of 40 years old presented a homogeneous distribution by decades of age. Some authors even suggest that dentists should be involved in the screening for HBP among younger patients, where the development of this disease is unusual (16).

There is a clear and positive correlation between levels of blood pressure and weight, which begins to be detected in childhood and adolescence $(17,18)$. Of the 45 patients with hypertension who took part in this study, $32(71.1 \%)$ had a body mass index $(\mathrm{BMI}) \geq 25$ (we recommend maintaining a BMI range of $18.5-24.9 \mathrm{~kg} / \mathrm{m} 2$ ) (4).

Several population studies have indicated that increased physical activity is inversely proportional to cardiovascular mortality in the long term. The practice of moderately intense physical activity reduces the future risk of presenting HBP and its progression, resulting in a favorable effect in reducing early mortality $(19,20)$. Of the 45 hypertensive patients who took part in this study, only $7(15.5 \%)$ practiced some form of physical activity (we recommend regular aerobic exercise, like brisk walking, at least half an hour a day, almost everyday of the week) (4). 


\section{Conclusions}

The results of this study show the importance of the dentist's role in detecting both undiagnosed hypertensive patients, as well as those who have previously been diagnosed as hypertensive, but who do not have their blood pressure under adequate control. The screening for HBP, especially in those over the age of 40 years old (especially if there are associated risk factors such as being overweight or sedentary), would enable early diagnosis of this condition, which could facilitate its control and reduce morbidity and mortality.

\section{References}

1. Berman CL, Guarino MA, Giovannoli SM. High blood pressure detection by dentists. J Am Dent Assoc. 1973;87:359-63.

2. Villar Alvarez F, Banegas Banegas JR, Rodríguez Artalejo F, Del Rey Calero J. Cardiovascular mortality in Spain and its autonomous communities (1975-1992). Med Clin (Barc). 1998;110:321-7.

3. Lewington S, Clarke R, Qizilbash N, Peto R, Collins R. Prospective Studies Collaboration. Age-specific relevance of usual blood pressure to vascular mortality: a meta-analysis of individual data for one million adults in 61 prospective studies. Lancet. 2002;360:190313.

4. Chobanian AV, Bakris GL, Black HR, Cushman WC, Green LA, Izzo JL Jr, et al. Joint National Committee on Prevention, Detection, Evaluation, and Treatment of High Blood Pressure. National Heart, Lung, and Blood Institute; National High Blood Pressure Education Program Coordinating Committee. Seventh report of the Joint National Committee on Prevention, Detection, Evaluation, and Treatment of High Blood Pressure. Hypertension. 2003;42:1206-52.

5. Tormo MJ, Navarro C, Chirlaque MD, Barber X. Validation of self diagnosis of high blood pressure in a sample of the Spanish EPIC cohort: overall agreement and predictive values. EPIC Group of Spain. J Epidemiol Community Health. 2000;54:221-6.

6 . Little JW. The impact on dentistry of recent advances in the management of hypertension. Oral Surg Oral Med Oral Pathol Oral Radiol Endod. 2000;90:591-9.

7. Herman WW, Konzelman JL Jr, Prisant LM; Joint National Committee on Prevention, Detection, Evaluation, and Treatment of High Blood Pressure. New national guidelines on hypertension: a summary for dentistry. J Am Dent Assoc. 2004;135:576-84.

8. Gordy FM, Le Jeune RC, Copeland LB. The prevalence of hypertension in a dental school patient population. Quintessence Int. 2001;32:691-5.

9. Margaix Muñoz M, Jiménez Soriano Y, Poveda Roda R, Sarrión G. Cardiovascular diseases in dental practice. Practical considerations. Med Oral Patol Oral Cir Bucal. 2008;13:E296-302.

10. Mancia G, De Backer G, Dominiczak A, Cifkova R, Fagard R, Germano G, et al. Management of Arterial Hypertension of the European Society of Hypertension; European Society of Cardiology. 2007 Guidelines for the Management of Arterial Hypertension: The Task Force for the Management of Arterial Hypertension of the European Society of Hypertension (ESH) and of the European Society of Cardiology (ESC). J Hypertens. 2007;25:1105-87.

11. Miyawaki T, Nishimura F, Kohjitani A, Maeda S, Higuchi H, Kita F, et al. Prevalence of blood pressure levels and hypertension-related diseases in Japanese dental patients. Community Dent Health. 2004;21:134-7.

12. Thompson AL, Collins MA, Downey MC, Herman WW, Konzelman JL Jr, Ward ST, et al. Prevalence and severity of hypertension in a dental hygiene clinic. J Contemp Dent Pract. 2007;8:13-20.

13. Márquez-Contreras E, Coca A, de la Figuera von Wichmann M, Divisón JA, Llisterri JL, Sobrino J, et al. Cardiovascular risk profile of uncontrolled hypertensive patients. The Control-Project study. Med Clin (Barc). 2007;128:86-91.
14. Abbey LM. Screening for hypertension in the dental office. J Am Dent Assoc. 1974;88:563-7.

15. Gabriel R, Alonso M, Bermejo F, Muñiz J, López I, Suárez C, et al. Proyecto EPICARDIAN. Estudio epidemiológico sobre enfermedades y factores de riesgo cardiovasculares en ancianos españoles: diseño, métodos y resultados preliminares. Rev Esp Geriatr Gerontol. 1996;31:327-34.

16. Pyle MA, Lalumandier JA, Sawyer DR. Prevalence of elevated blood pressure in students attending a college oral health program. Spec Care Dentist. 2000;20:234-9.

17. Wolf HK, Tuomilehto J, Kuulasmaa K, Domarkiene S, Cepaitis $\mathrm{Z}$, Molarius A, et al. Blood pressure levels in the 41 populations of the Who Monica Project. J Hum Hypertens. 1997;11:733-42.

18. Lurbe E, Alvarez V, Liao Y, Tacons J, Cooper R, Cremades B, et al. The impact of obesity and body fat distribution on ambulatory blood pressure in children and adolescents. Am J Hypertens. 1998;11:418-24.

19. Palatini P, Graniero GR, Mormino P, Nicolosi L, Mos L, Visentin $\mathrm{P}$, et al. Relation between physical training and ambulatory blood pressure in stage I hypertensive subjects. Results of the HARVEST Trial. Hypertension and Ambulatory Recording Venetia Study. Circulation. 1994;90:2870-6.

20. Paffenbarger RS Jr, Lee IM. Intensity of physical activity related to incidence of hypertension and all-cause mortality: an epidemiological view. Blood Press Monit. 1997;2:115-23. 